\title{
Le rôle du clergé canadien dans l'éducation de 1760 à 1914
}

\section{Claude Galarneau}

Volume 34, 1967

URI : https://id.erudit.org/iderudit/1007424ar

DOI : https://doi.org/10.7202/1007424ar

Aller au sommaire du numéro

Éditeur(s)

Les Éditions Historia Ecclesiæ Catholicæ Canadensis Inc.

ISSN

0318-6172 (imprimé)

1927-7067 (numérique)

Découvrir la revue

Citer cet article

Galarneau, C. (1967). Le rôle du clergé canadien dans l'éducation de 1760 à

1914. Sessions d'étude - Société canadienne d'histoire de l'Église catholique, 34,

75-78. https://doi.org/10.7202/1007424ar

Tous droits réservés @ Les Éditions Historia Ecclesiæ Catholicæ Canadensis Inc., 1968
Ce document est protégé par la loi sur le droit d'auteur. L'utilisation des services d'Érudit (y compris la reproduction) est assujettie à sa politique d'utilisation que vous pouvez consulter en ligne.

https://apropos.erudit.org/fr/usagers/politique-dutilisation/ 


\section{Le rôle du clergé canadien dans l'éducation de 1760 à 1914 *}

Connaître « l'attitude que le clergé a manifestée envers l'éducation et la place qu'il a effectivement occupée ", tels sont les points importants que Claude Galarneau développe dans sa communication sur le Rôle $d u$ clergé dans l'éducation de 1760 à 1914.

\section{Sabordage d'une planification scolaire}

$\mathrm{Au}$ cours du régime français, M. Galarneau note que l'Eglise assure l'enseignement en grande partie. Cependant, il n'existe pas de système scolaire comme tel. Pour pallier à cette carence, Lord Dorchester, en 1787, "institue la première commission d'enquête dont le mandat est de suggérer les meilleurs moyens aptes à promouvoir l'instruction élémentaire ». Une polémique entre $\mathbf{M}^{\mathrm{gr}}$ Bailly et $\mathbf{M}^{\mathrm{gr}}$ Hubert noie le projet.

\section{Un clergé anti-gratuité scolaire}

En 1801, un a acte pour établir des écoles gratuites et pour le progrès de l'instruction 》 est présenté et voté à la Chambre d'assemblée. L'évêque de Québec et les curés s'opposèrent à cette loi qui « donne au gouvernement et à l'institution royale des pouvoirs très étendus et constitue un véritable système d'enseignement public régi par l'Etat ». Opposition, par crainte du protestantisme. a Il est possible que leur crainte ait été outrée ou fondée comme il se peut que l'éducation des Canadiens français ait subi un retard de trente ou quarante ans. .

\section{Apathie des curés}

Dans une lettre au grand vicaire Roux, de Montréal, en 1809, $\mathbf{M}^{\mathrm{gr}}$ Plessis déplore « l'apathie inconcevable des curés » face à l'éducation. D'ailleurs, cette attitude est encore manifestée en 1824 devant la loi dite des écoles de fabrique, même si l'évêque donne son assentiment. Cette loi érige l'organisation scolaire sur une base paroissiale.

\section{Boycottage d'un projet d'écoles normales}

En 1829, la Chambre d'assemblée passe une autre loi qui donne le coup de grâce à celle de 1801. Cette loi des écoles d'assemblée ou de

* On lira ici un résumé de la conférence de Monsieur Claude Galarneau. Monsieur Galarneau avait donné cette conférence au Colloque des Etudiants en Histoire de l'Université Laval, en février 1967. Ce résumé, dû à MM. Georges Massey et Gaston Tisdel, a paru dans le journal a Le Carabin *, supplément du $n^{\circ}$ du 16 février 1967, p. 4. Monsieur Galarneau a apporté certaines corrections minimes au texte du résumé. Le conférencier prépare un ouvrage qui sera intitulé : . La France devant l'opinion canadienne de 1760 à 1855. . 
syndics « permet aux contribuables des paroisses d'élire des syndics chargés de veiller à la construction et à la direction immédiate de l'école, confie au député la surveillance générale des écoles du comté et donne à la Chambre d'assemblée le pouvoir de leur verser des subventions ». Cette loi, suspendue en 1836, permet la création de nombreuses écoles et, conséquemment, montre " la grande pénurie de maîtres et leur manque de préparation». Pour combler cette lacune, on tente alors de créer des écoles normales, qui ne seront effectivement en service qu'en 1856.

\section{Un mort-né : le ministère de l'Instruction publique}

* La loi de 1856 reconnaît encore la nécessité de créer un conseil de l'Instruction publique, qui est mis sur pied trois ans après sur une base mixte, comprenant 10 catholiques et 14 protestants. En 1869, la séparation confessionnelle est établie au sein même de cet organisme avec un comité catholique et un comité protestant. »

En 1874, Boucherville devient premier ministre et garde, comme Chauveau, le ministère de l'Instruction publique. Au début de 1875, il demande à $\mathbf{M}^{\mathrm{gr}}$ Taschereau de consulter les évêques à propos de la refonte de la loi scolaire. Il s'agit d'instituer un conseil de l'Instruction publique.

\section{L'éducation, monopole du clergé}

L'évêque de Québec, dans le douzième article de son questionnaire, demande si "les évêques devraient tous être membres ex officio du conseil ». $M^{\mathrm{gr}}$ Laflèche répond que non seulement "il veut que les évêques soient membres d'office du conseil, mais encore, il propose qu'un article devrait reconnaître que le droit des évêques de contrôler les écoles ne leur soit pas confié par le pouvoir civil mais, au contraire, reconnu par lui ».

Toujours en rapport avec ce projet de loi, $\mathrm{M}^{\mathrm{gr}}$ Moreau, de SaintHyacinthe, écrit : « (...) il me répugne de voir tous les évêques d'une même province réunis en assemblée et ayant un laïc pour président, et surtout pour traiter de questions et de matières qui sont uniquement de leur ressort, puisque l'instruction et l'enseignement appartiennent de droit à l'Eglise (...) ». Finalement, le ministère de l'Instruction publique est aboli et remplacé par un surintendant : Boucherville alléguant "qu'un ministre y connaît peu de chose et qu'il est trop chargé de besogne pour s'en occuper efficacement ».

\section{La possession de la vérité}

En 1897, les libéraux reprennent le pouvoir et veulent ressusciter le ministère. Un "tollé 》 de protestations soulèvent l'Episcopat canadien. En dépit des interventions de $\mathbf{M}^{\mathrm{gr}}$ Bruchési auprès du pape, le projet de loi est présenté mais battu devant le Conseil législatif. Sentencieusement, $\mathbf{M}^{\mathrm{gr}}$ Bruchési écrit à Chapais : "Vous avez tué le bill. 
Ces ministres devront comprendre maintenant quelle faute ils ont commise en ne suivant pas mes conseils et en ne se rendant pas à ma demande.

M. Galarneau aborde le second point de son exposé en disant qu'on a vu le clergé passer peu à peu de la réserve à l'attaque, de la faiblesse à la puissance devant les lois scolaires. Il se propose alors a d'évaluer la présence, de mesurer la place qu'occupe le clergé dans les trois ordres d'enseignement primaire, secondaire et supérieur ».

\section{Multiplication des communautés religieuses}

Selon les recherches de l'abbé Amédée Gosselin, il estime que le clergé dirige 24, écoles élémentaires sur 47 en 1760 , de même que 5 ou 6 écoles spéciales, écoles dirigées par 9 communautés religieuses différentes. Les chiffres de M. Galarneau montrent que " 13 communautés ont été fondées au Québec entre 1840 et 1914, toutes féminines; 68 sont venues de France, dont 9 instituts de frères, 20 de religieux prêtres et 39 de religieuses, ce qui fait un total de 81 instituts religieux installés dans l'enseignement pour la seconde partie du siècle, soit entre 1837 et 1914, auxquels il faut ajouter les 6 communautés qui ont survécu au régime français, soit donc en tout 87 communautés ». Le conférencier ajoute que 62 communautés s'installent dans l'enseignement primaire.

\section{Pourcentage du clergé dans l'enseignement élémentaire}

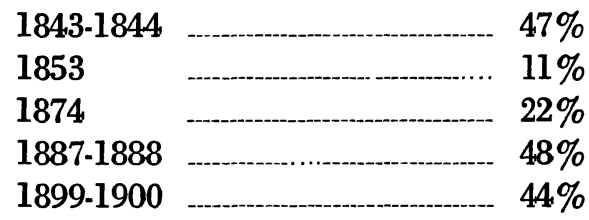

Château-fort du clergé

Le directeur de l'Institut d'histoire aborde l'enseignement secondaire classique en affirmant que c'est " la seule forme d'enseignement secondaire organisé " et que "le clergé occupe toute la place ".

Entre 1765 et 1914, 31 collèges classiques ou juvénats ont vu le jour, dont 2 seulement comptent parmi leurs fondateurs un laïc. Il y a quelques laïcs qui enseignent dans la plupart de ces collèges, mais ce n'est que par accident, et pour des matières comme la musique, le dessin ou l'anglais.

A cause de la carence de notre historiographie, il est impossible de mesurer qualitativement la fonction du clergé dans l'éducation.

Cependant, le conférencier considère comme un a extraordinaire apport " l'arrivée des prêtres et des religieux français au Québec entre 1793 et 1914. 


\section{L'enseignement supérieur, ce mal-aimé}

Les laïcs sont « fort actifs " pendant la première partie du siècle. "Les jeunes qui se destinent aux professions libérales font leur apprentissage auprès des médecins, des avocats ou des notaires en exercice." Des cours de Droit sont dispensés par des avocats, tant à Montréal qu'à Québec; d'autre part, des écoles de médecine sont crées dans ces deux villes en 1842 et en 1848. La fondation de l'Institut canadien en 1844 est non moins importante.

Toutefois, ce n'est qu'en 1852 que l'université Laval est fondée, et en 1876 qu'on permettra l'établissement de sa succursale à Montréal. Pour sa part, M. Galarneau considère que "l'histoire de l'enseignement supérieur reste à faire en entier ».

\section{Un clergé apeuré, prépotent et "patroneux»}

En concluant sur le rôle du clergé au $\mathrm{XIX}^{\bullet}$ siècle en éducation, M. Galarneau qualifie son comportement comme "marqué au coin de la peur : peur du protestantisme jusqu'au milieu du XIX' siècle, peur des laïcs et du laïcisme, peur de l'Etat dans la seconde partie ».

Il poussa plus loin sa pensée en disant que le clergé a développé " une véritable prépotence morale qui a submergé la collectivité canadienne-française, de sorte qu'il a pu aller jusqu'au coup de force de 1897-98, forçant à toutes fins pratiques l'Etat à abdiquer et à se contenter de demi-mesures et le plus souvent par les procédés obliques du " patronage politique ». 